\title{
Simulations of deep convection in the Mediterranean area using 3DVAR of conventional and non-conventional data
}

\author{
R. Ferretti ${ }^{1,2}$, C. Faccani ${ }^{1}$, D. Cimini ${ }^{1}$, F. S. Marzano ${ }^{3,2}$, A. Memmo ${ }^{2}$, L. Cucurull ${ }^{4}$, and R. Pacione ${ }^{5}$ \\ ${ }^{1}$ Department of Physics, University of L'Aquila, Italy \\ ${ }^{2}$ CETEMPS, University of L'Aquila, Italy \\ ${ }^{3}$ Department of Electrical Engineering, University of L'Aquila, Italy \\ ${ }^{4}$ COSMIC Project SCSDA, Suitland, MD 20746, USA \\ ${ }^{5}$ Telespazio SPA, Centro di Geodesia Spaziale, Matera, Italy
}

Received: 24 October 2004 - Revised: 14 February 2005 - Accepted: 16 February 2005 - Published: 29 March 2005

\begin{abstract}
In autumn deep convection in the Mediterranean region is a common phenomenon. The local events characterized by deep convection are still a difficult task even for high resolution numerical weather prediction. Three flood cases, produced by convection either embedded in a large scale system or locally developed, occurring in Italy, are presented. All these case were not correctly forecasted: Sardinia (Cagliari, 13 November 1999); Calabria (Soverato, 7 September 2000) and Sicily (Catania, 16 September 2003). The first case occurred during the Mesoscale Alpine Programme (MAP) campaign, therefore a lot of data are available; for the second one only data from SSM/I and local rain-gauge are available; the third one occurred during the operational experimentation of the TOUGH project. The last one was not well predicted even using the operational assimilation of ground based GPS. To improve the forecast of these cases the assimilation of several data is tested. The variational assimilation performed using 3DVAR of GPS, SSM/I and surface and upper air data is applied to improve the Initial Conditions of the Sicily case. The Sardinia case is improved using either GPS and surface data, whereas for the Soverato case only ZTD is assimilated. The experiments are performed using the MM5 model from Pennsylvania State University/National Center for Atmospheric Research (PSU/NCAR); the model is initialized using the new Initial Conditions produced by the variational assimilation of conventional and non conventional data. The results show that the assimilation of the retrieved quantities does produces large improvement in the precipitation forecast. Large sensitivity to the assimilation of surface data and brightness temperature from SSM/I is found.
\end{abstract}

\section{Introduction}

The numerical weather prediction of deep convection is still a difficult task for the Mediterranean region. Unfortunately, as the autumn starts moisten laden air blowing from south is likely to produce severe weather events (Doswell III et al., 1998). The uplifting of warm and humid air, produced either by the mountain barrier (as the Alps) or by convergence locally developed (Buzzi et al., 1998; Rotunno and Ferretti, 2003, 2001), are the concurring factor to the heavy precipitation events. Another concurring factor, to heavy precipitation, is deep convection embedded in to the large scale storms, as well as the convective system locally developed. The exact forecast, i.e. location and timing, is still affected by a large error even using high resolution models. Recently, the variational data assimilation has been used to correct the phase error that affect the high resolution forecast. A recent study by Ferretti and Faccani (2005) showed that the assimilation of high density (spatial and time) observations allows to correct the precipitation forecast even if the new set of mesoscale Initial Condition is even worst than the one without assimilation (Faccani and Ferretti, 2004). Based on this results, a study on the impact of the assimilation of either conventional and non conventional data is performed for three cases of heavy precipitation occurred in Italy. The assimilation of several kind of data is performed to asses the impact of the different measurements on the forecast of the precipitation. The cases are: Sardinia (Cagliari), 13 November 1999; Calabria (Soverato), 8 October 2000; Sicily (Catania), 16 September 2003. All these cases produced a flood, sever damages and lost of human life; therefore, the correct forecast of these event is imperative. 


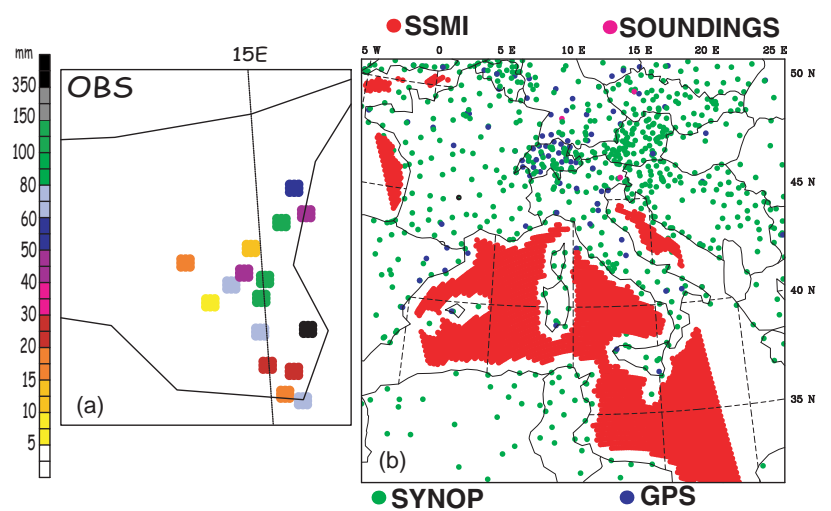

Fig. 1. Distribution of: (a) the observed precipitation for Sicily case; (b) the observations used for the assimilation.

\section{Experiment design and assimilation technique}

A few experiments are performed to evaluate the impact of either conventional and non conventional data on the precipitation forecasts. The data used for these experiments depends on the availability of the data for the events. The measurements used are:

1. Ground based GPS: Precipitable water (PW) and ZTD

\section{SSM/I: Brightness Temperature (TB)}

3. Surface data: temperature and wind

4. Radiosonde: temperature, wind and humidity

The conventional observations either the surface data (temperature, dew point temperature, and wind) and upper air are assimilated in to the ECMWF analyses that are used as first guess Faccani and Ferretti (2004). The non conventional data used for the experiments are: TB retrieved by SSM/I, ZTD and/or PW from ground based GPS. The lack of observations over the Mediterranean sea makes the SSM/I data very useful (Fig. 1). For details on the algorithm used to assimilate the SSM/I Brightness see Faccani et al. (2005).

The 3-Dimensional Variational Data Assimilation (Courtier et al., 1998; Gustafsson et al., 2001; Barker et al., 2004) is used to generate the new mesoscale Initial Conditions by assimilating all the available data. 3DVAR assimilates the data by minimizing the cost function $J$ defined as

$$
\begin{aligned}
J= & \frac{1}{2}\left(x^{b}-x\right)^{T} \mathbf{B}^{-1}\left(x^{b}-x\right)+ \\
& \frac{1}{2}\left(y^{o}-H\left(x^{b}\right)\right)^{T} \mathbf{R}^{-1}\left(y^{o}-H\left(x^{b}\right)\right)
\end{aligned}
$$

where $x^{b}$ is the generic variable of the first guess, $y^{o}$ is the observation, and $H$ is the operator that converts the model state variables to the observed variables at the observation location. $\mathbf{B}$ and $\mathbf{R}$ are the error covariance matrices for the first guess and for the errors, respectively. The solution of

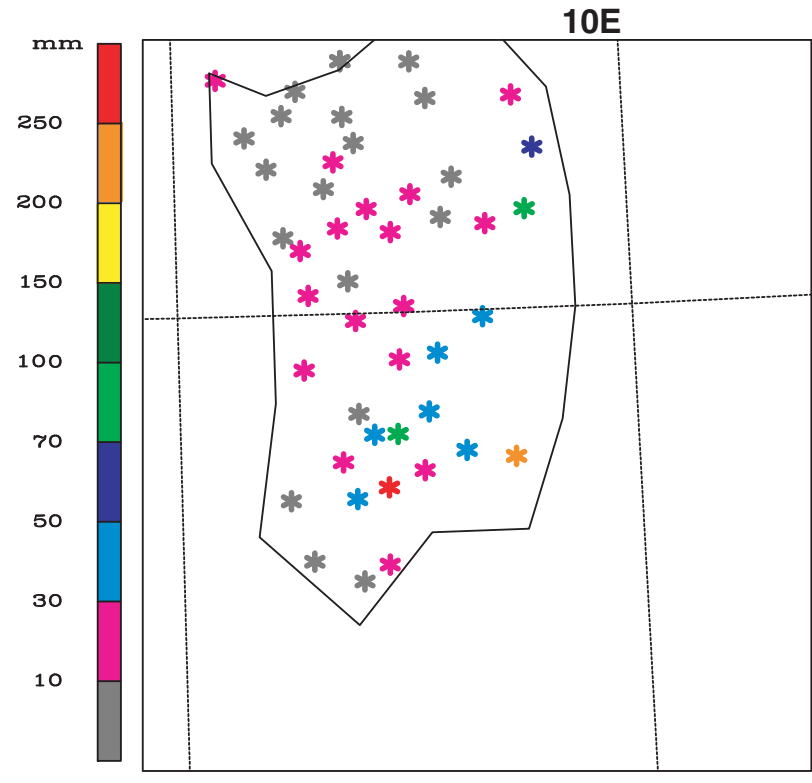

Fig. 2. Observed precipitation for Sardinia case.

the minimization produces the new set of mesoscale Initial Conditions.

In this study, the ECMWF (European Center for MediumRange Weather Forecast) analysis are used as first guess.

The new set of mesoscale Initial and Boundary Conditions generated by 3DVAR are in Table 1 together with the mesoscale model experiments. In the first column there are the acronyms used for the MM5 experiments. CNTR is the case without any data assimilation: i.e. the ECMWF analysis are interpolated to the model grid. TB refers to the assimilation of the SSM/I retrieved Brightness Temperature. The experiments performed using the ground based GPS by assimilating either directly the ZTD or the retrieved precipitable water are respectively ZTD and PW. The FDDA experiment refers to the assimilation of precipitable water using nudging technique. The assimilation of convectional surface and upper air (synop and sonde) data is SU-UP. Finally, an experiment is performed by assimilating all these data (ALL). The data used for the experiments and their distribution on the region are shown in Fig. 1 b.

These experiments will allow for evaluating the impact of either any observations and all the observations.

\section{The cases: Sardinia, Calabria and Sicily}

The events analyzed in this study are characterized by deep convection, whose were not correctly forecasted.

The Sardinia case was characterized a large upper level cyclone extending from Spain to France associated to a low level depression over the western Mediterranean sea in the evening of 11 November 1999. During the following $24 \mathrm{~h}$ the system moved eastward and intensified, producing advection of warm moist laden air toward Sardinia Island. During the 
Table 1. Experiments performed and data used.

\begin{tabular}{lccccc}
\hline \multicolumn{5}{c}{ Assimilated observations } \\
EXP & TB & GPS PW & GPS ZTD & synop & sonde \\
\hline CNTR & - & - & - & - & no \\
SSM/I & yes & no & no & no & no \\
PW & no & yes & no & no & no \\
ZTD & no & no & yes & no & no \\
FDDA & no & yes & no & no & no \\
SU-UP & no & no & no & yes & yes \\
ALL & yes & no & yes & yes & yes \\
\hline
\end{tabular}

nigh between 12 and 13 November 1999 (Fig. 3a), the upper level minimum tilted its axis allowing for advection of cold air, whereas advection of warm air was still present at lower level. The interaction of the two air masses over Sardinia allowed for developing convection enhanced by the orographic uplifting. The rain-gauge recorded a maximum of rainfall at Cagliari station was greater than $250 \mathrm{~mm}$ (Fig. 2).

The Soverato (Calabria) event occurred at the beginning of September 2000. During 7 September an upper level trough allowed for northwesterly wind over the Italian regions. At the surface a deep low was located over the Gulf of Genoa; during the following day the surface low was advected southwestward and intensified. In the early morning of 8 September 2000 the minimum reached Sicily advecting warm moist laden air toward Calabria. The upper cut off low allowed for the low level depression to became stationary for the following two days (Fig. 3b). Also in this case the convection developed over the sea and it was enhanced over the souther Italian Apennines: uplifting of the warm and moist air produce orographic precipitation. The rain-gauge recorded up to $300 \mathrm{~mm}$ between 9 and 10 September, 2000 (Fig. 6b, d); during the first hours of the following day the Chiaravalle station recorded $185.4 \mathrm{~mm}$ in $6 \mathrm{~h}$, the heavy rainfall caused a landslide over Soverato.

The Sicily event was characterized by a deep-low level pressure field located over the southern Mediterranean area, between Italy and Africa (Fig. 3c), at 12:00 UTC 16 September 2003. A flow of warm air was advected from east-southeast. Twelve hours later, the wind direction is unchanged; the low pressure over the Mediterranean area at surface is reduced, but a meso-low depression is still present at higher level. The infrared satellite images show that at 1800UTC September 16, 2003 there was an area of deep convection on the south of Sicily (not shown). In the following 12 hours, the whole Sicily was covered by clouds. The rainfall recorded at Syracuse until 05:30 UTC 17 September 2003 up was $425 \mathrm{~mm}$ in $7 \mathrm{~h}$ (Fig. 1a).
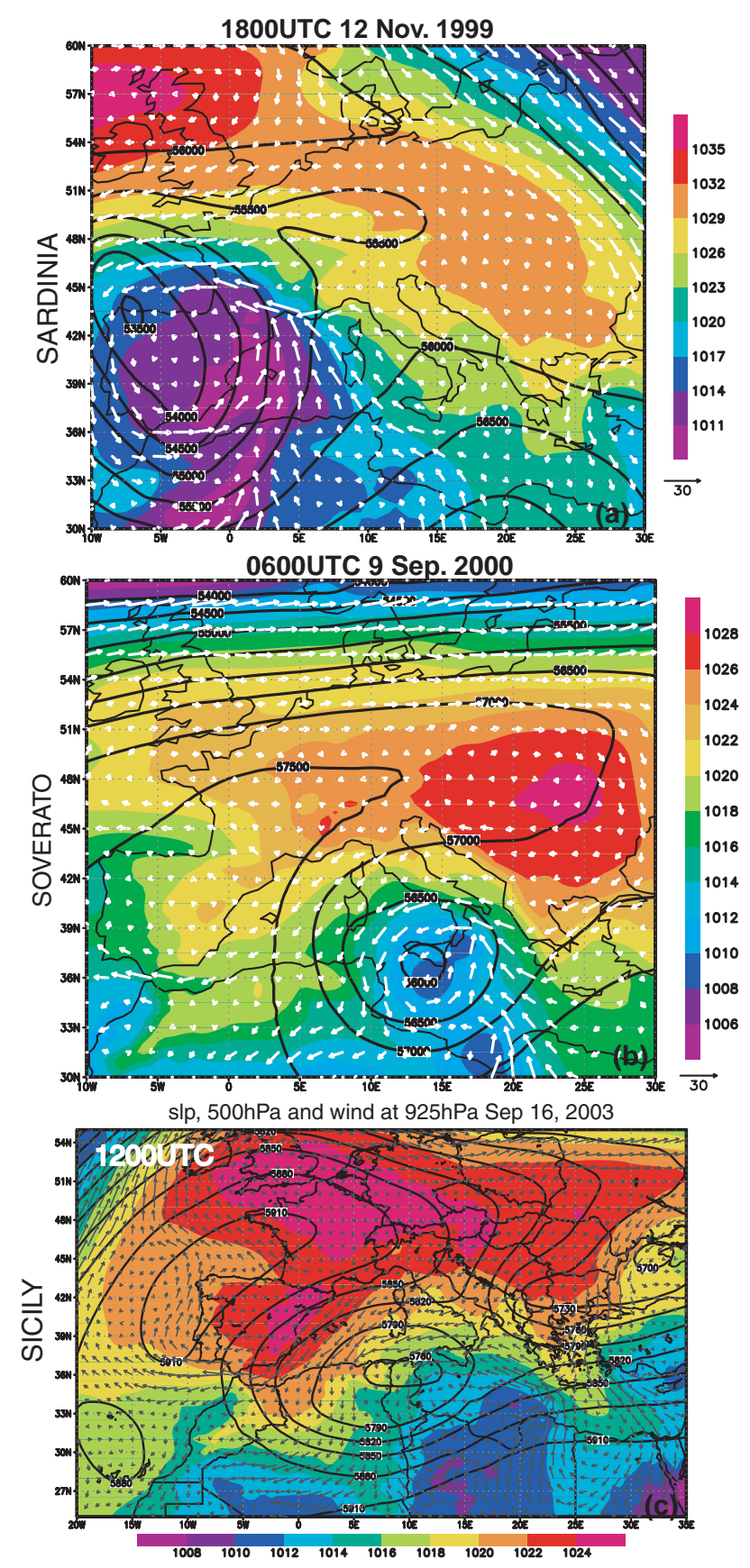

Fig. 3. ECMWF data analysis for: (a) the Sardinia case; (b) the Soverato case; (c) the Sicily case

\section{Model setup}

The model used for this study is the MM5 model version 3 from PSU/NCAR (Grell et al., 1994; Dudhia, 1993); MM5 is non hydrostatic, fully compressible at the primitive equations model. The model has the capability of nesting domains to enhance the resolution over the area of interest. In this study three/four nested domains are used: the mother domain has a resolution of $27 \mathrm{~km}$, the second one has a resolution of $9 \mathrm{~km}$ (Fig. 4) and the third domain has a resolution of $3 \mathrm{~km}$; the 


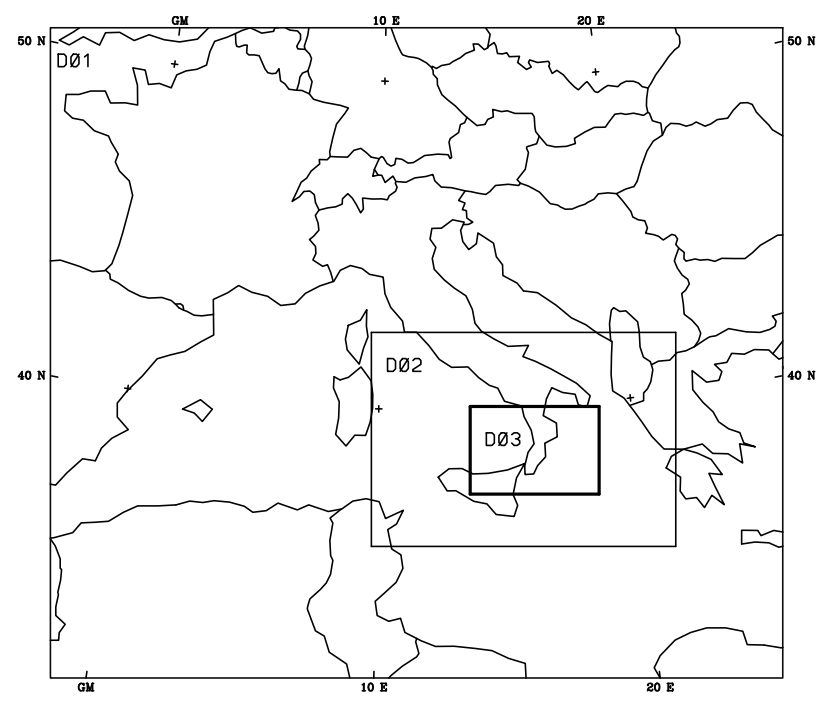

Fig. 4. Model domains; only domains 1, 2 and 3 (Soverato case) are plotted.

Table 2. Events and start time.

\begin{tabular}{lccc}
\hline \multirow{2}{*}{ EXP } & date & Starting at & Lasting \\
\hline Sardinia & 13 Nov. 1999 & $18: 00$ UTC & $48 \mathrm{~h}$ \\
Calabria & 8 Sep. 2000 & 12:00 UTC & $48 \mathrm{~h}$ \\
Sicily & 16 Sep. 2003 & 18:00 UTC & $30 \mathrm{~h}$
\end{tabular}

innermost reaches a resolution of $1 \mathrm{~km}$ (for Soverato case only). 29 (35 for the Soverato simulation) vertical $\sigma$ terrain following are used and the Hong and Pan (1996) and Troen and Mahrt (1986) parameterizations are used to describe the planetary boundary layer. Reisner et al. (1998) explicit moisture scheme is used for all domains, whereas it is associated to the Kain and Fritsch (1990) cumulus convection scheme for domains 1 and 2 only.

The new Initial Conditions for each experiment are shown in Table 1, and the starting and lasting time for each experiments are in Table 2.

\section{Precipitation Forecast}

The sensitivity of the precipitation forecast to the different set of data assimilated in to the Initial condition is presented for each event.

\subsection{Sardinia}

The precipitation forecast clearly shows an overall good agreement between MM5 and the observations (Fig. 2), but an underestimation of the rainfall is found in the Cagliari area (Fig. 5a), where the flood occurred. The precipitation

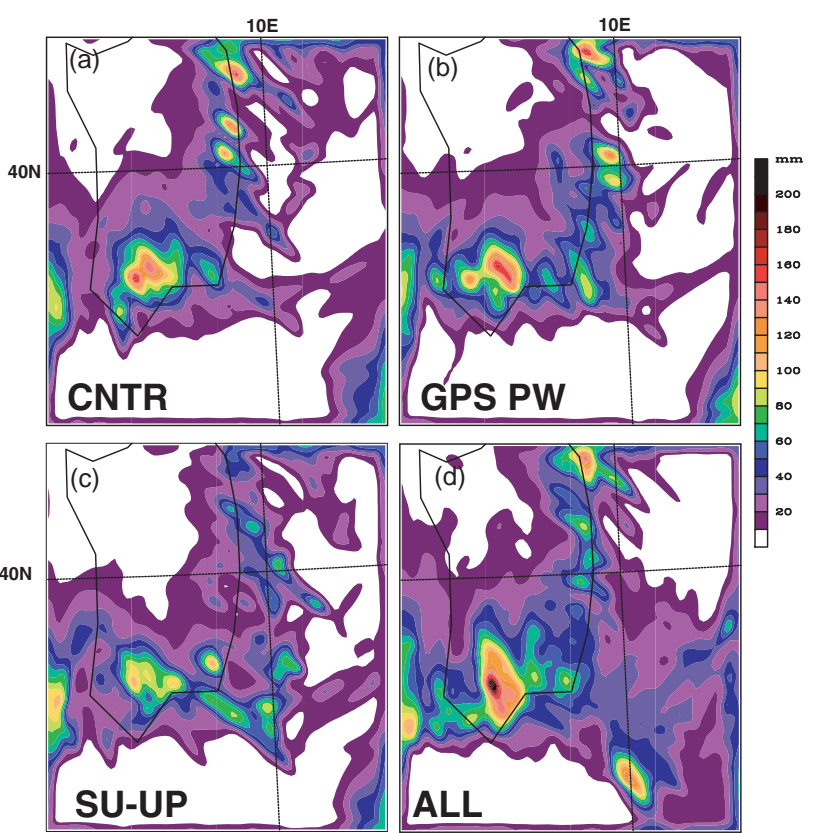

Fig. 5. $24 \mathrm{~h}$ accumulated precipitation produced by MM5 for: (a) CNTR; (b) assimilation of GPS PW; (c) assimilation of surface and upper air SU-UP; (d) assimilation of all the available data, ALL.

forecast shows large sensitivity to the assimilation of different data. The impact of ground based GPS PW allows for moving the rainfall eastward producing an increase of the precipitation in the Cagliari area (Fig. 5b), but along the east coast the rainfall is moved toward the sea largely reducing the precipitation along this coast. Viceversa the assimilation of only conventional data produces a large underestimation of the precipitation (Fig. 5c) in the Cagliari area, and along the eastern coast. The assimilation of all the observations allows for increasing the rainfall (Fig. 5d) over Cagliari reaching a maximum close to the observed one (Fig. 2), but widespread precipitation is also produced in the northwest of the region where no rainfall was observed.

The statistical evaluation is presented only for CNTR and ALL, because the two experiments show large differences and also because 'the by eyes' analysis would suggest ALL being much better than CNTR. The statistics clearly show an opposite results: CNTR has a very good skill in reproducing the rainfall, definitely better than ALL. This results, clearly in contrast with the by eyes analysis, it is probably driven by the widespread small overestimation of the precipitation by ALL in the northwest of the region.

\subsection{Calabria}

The comparison between the precipitation forecast and the analyzed observation (Fig. 6a, b) clearly shows the MM5 phase error in time and, with minor extent, in space. Beside the fair agreement between model and observation in the first stage of the event the model anticipate the maximum of the precipitation of several hours; in the following 
Table 3. Statistical evaluation for Sardinia case. Experiments performed using: ECMWF data analyses for CNTR; Data assimilation of all the available data ALL.

\begin{tabular}{lccc}
\hline EXP & Mean & RMS & STDEV \\
\hline CNTR & 1.43 & 52.15 & 52.13 \\
ALL & -7.16 & 54.19 & 53.72 \\
\hline
\end{tabular}

hours a reduction of the total rainfall is produced by the model whereas the maximum of the precipitation is observed (Fig. 6d). The assimilation of GPS ZTD allows for reducing the precipitation, with respect to CNTR (not shown) during the first stage, producing a better agreement with the observations. On the other hand in the following hours an underestimation of the precipitation is found. The higher resolution $(1 \mathrm{~km})$ forecast does not allow for correcting the phase error in time (not shown). Clearly, a tendency to overestimate the precipitation in the upwind side of the mountain is found for all the experiments.

A few statistical parameters are used to compare the experiments: the one used as reference CNTR, the second one performed using 3DVAR (ZTD) and the last one using 4 nested domains (RES), but for consistency only the precipitation feed back to domain 3 is accounted. During the first phase of this event the statistics clearly show an improvement of the rainfall if ZTD is assimilated. But large error is found for all the experiments suggesting, as already pointed out, a large overestimation because of the model anticipating the maximum rainfall. During the second phase the mean error is largely reduced showing a small overestimation of rainfall for CNTR. Still large error are found for the two other experiments. The root mean square error (Rms) and the standard deviation (STDEV) show large values for all the experiments, suggesting a large uncertainty for all of them. It has to be pointed out that the assimilation of GPS ZTD tries to correct the model failure by reducing the precipitation during the first phase and viceversa increasing it during the second one.

\subsection{Sicily}

Also in this case the MM5 forecast shows good skill in reproducing the event. An underestimation of the rainfall in the flood area is produced by CNTR (Fig. 7a), but the location is approximately correct (Fig. 1a). Results similar to CNTR are obtained either if PW is assimilated using nudging technique (FDDA) or the conventional data are assimilated by 3DVAR (both not shown). The assimilation of GPS ZTD allows for enlarging and displacing the area of the maximum precipitation southward (Fig. 7b); whereas the assimilation of SSM/I produces a remarkable increase of either the area of the maximum precipitation and the rainfall itself (Fig. 7c). Moreover, the TB experiment produces a spiral structure of
Table 4. Statistical evaluation for Soverato case. Experiments performed using: ECMWF data analyses for CNTR; Data Assimilation of ZTD; 4 domains for RES.

\begin{tabular}{lccr}
\hline \multicolumn{5}{c}{ 24h acc ending at 00:00, 10 Sep } \\
\hline EXP & Mean & RMS & STDEV \\
\hline CNTR & -98.92 & 152.39 & 115.93 \\
ZTD & 76.12 & 136.17 & 112.91 \\
RES & -129.23 & 179.66 & 124.81 \\
& & & \\
& & 24h acc ending at 12:00, 10 Sep & \\
\hline & & RMS & STDEV \\
EXP & Mean & 122.88 & 122.66 \\
CNTR & 7.51 & 126.30 & 123.45 \\
ZTD & 26.67 & 136.50 & 135.99 \\
RES & -11.87 & &
\end{tabular}

Table 5. Statistical evaluation for Sicily case. Experiments performed using: ECMWF data analyses for CNTR; Data Assimilation of Brightness temperature TB; data assimilation of GPS ZTD or PW; assimilation of PW by FDDA; assimilation of surface and upper air SU-UP; assimilation of available data ALL.

\begin{tabular}{lccc}
\hline EXP & Mean & RMS & STDEV \\
\hline CNTR & 38.29 & 91.96 & 83.61 \\
TB & 31.49 & 85.57 & 79.56 \\
PW & 57.38 & 104.61 & 87.47 \\
ZTD & 36.07 & 86.14 & 79.33 \\
FDDA & 36.48 & 89.40 & 81.61 \\
SU-UP & 39.96 & 87.23 & 77.54 \\
ALL & 38.61 & 93.56 & 85.22 \\
\hline
\end{tabular}

the rainfall region resembling the cyclone structure. Finally, the assimilation of all the data slightly reduces the region of the maximum rainfall, but a structure similar to the SSM/I one is maintained (Fig. 7d).

To better evaluate the impact of the assimilation of each measurements the statistical parameter are used. The mean error and the root mean square error suggest that a remarkable reduction of the error is obtained if assimilation of TB by SSM/I is applied (Table 5). 


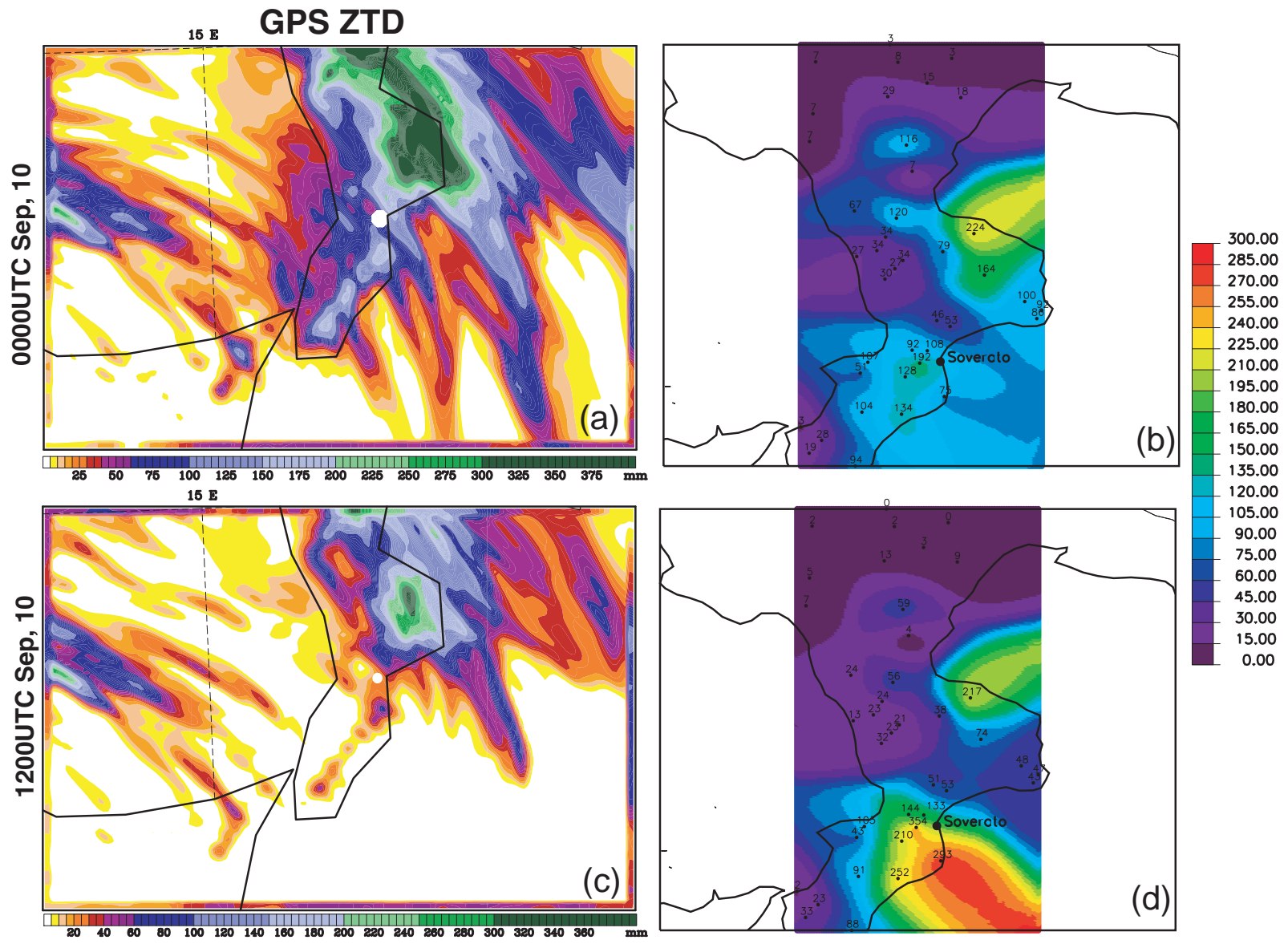

Fig. 6. $24 \mathrm{~h}$ accumulated precipitation for GPS ZTD Soverato case. The precipitation ends at 00:00 UTC, 10 Sep: (a) ZTD; (b) Observation. The precipitation ends at 12:00 UTC, 10 Sep: (c) ZTD; Observation.

\section{Conclusions}

The aim of this paper was to evaluate the impact of conventional and non-conventional data on the precipitation forecast of deep convection in the Mediterranean region. The data used for the assimilation are: Brightness Temperature from SSM/I data; PW or ZTD from ground based GPS; surface and sounding data. Three cases of deep convection are used as test cases, all events produced heavy rainfall and localized flood. The model simulations show an overall good agreement with the observations, but the position and the timing of the cells are not perfectly forecasted. The Sardinia case shows a very good forecast if all the available data are assimilated, unfortunately the statistics does not confirm this results. Indeed, CNTR shows the lowest error. The assimilation of GPS ZTD for Soverato case does not allow to correct the phase error in time; the statics confirm this results by producing large error during the first phase for all the experiments, but slightly reducing it for ZTD. The large STDEV and RMS suggest an overall large uncertainty in the forecast. Finally, the Sicily case shows a large impact of the assimilation especially for the TB experiment. The comparison among the statistical parameters computed for the Sicily case for the different experiments suggests the assimilation of SSM/I data as the one producing the best results. These results are not exhaustive for a assessing the impact of the non-conventional data on the operational weather forecast. More events have to be analyzed and operational testing allowing for a statistical evaluation has to be performed.

Acknowledgements. A special thank to all the Sicily Region, SAR Sardinia and Centro Idrografico Calabria for rain data. Thank to NCAR for the MM5 model and to the MAP archive for the surface and upper-air data. Thank to ECMWF for the data analysis.

Edited by: L. Ferraris

Reviewed by: anonymous referees

\section{References}

Barker, D. M., Huang, W., Guo, Y.-R., Bourgeois, A., and Xiao, Q.: Three-Dimensional Variational Data Assimilation System for MM5: Implentation and initial results, Mon. Wea. Rev., 132, 897-914, 2004.

Buzzi, A., Tartaglione, N., and Malguzzi, P.: Numerical simulations of the 1994 Piedmont flood: Role of orography and moist processes, Mon. Wea. Rev., 126, 2369-2383, 1998.

Courtier, P., Anderson, E., Heckley, W., Pailleux, J., Vasiljeric, D., Hamrud, M., Hollingsworth, A., Rabier, F., and Fisher, M.: 

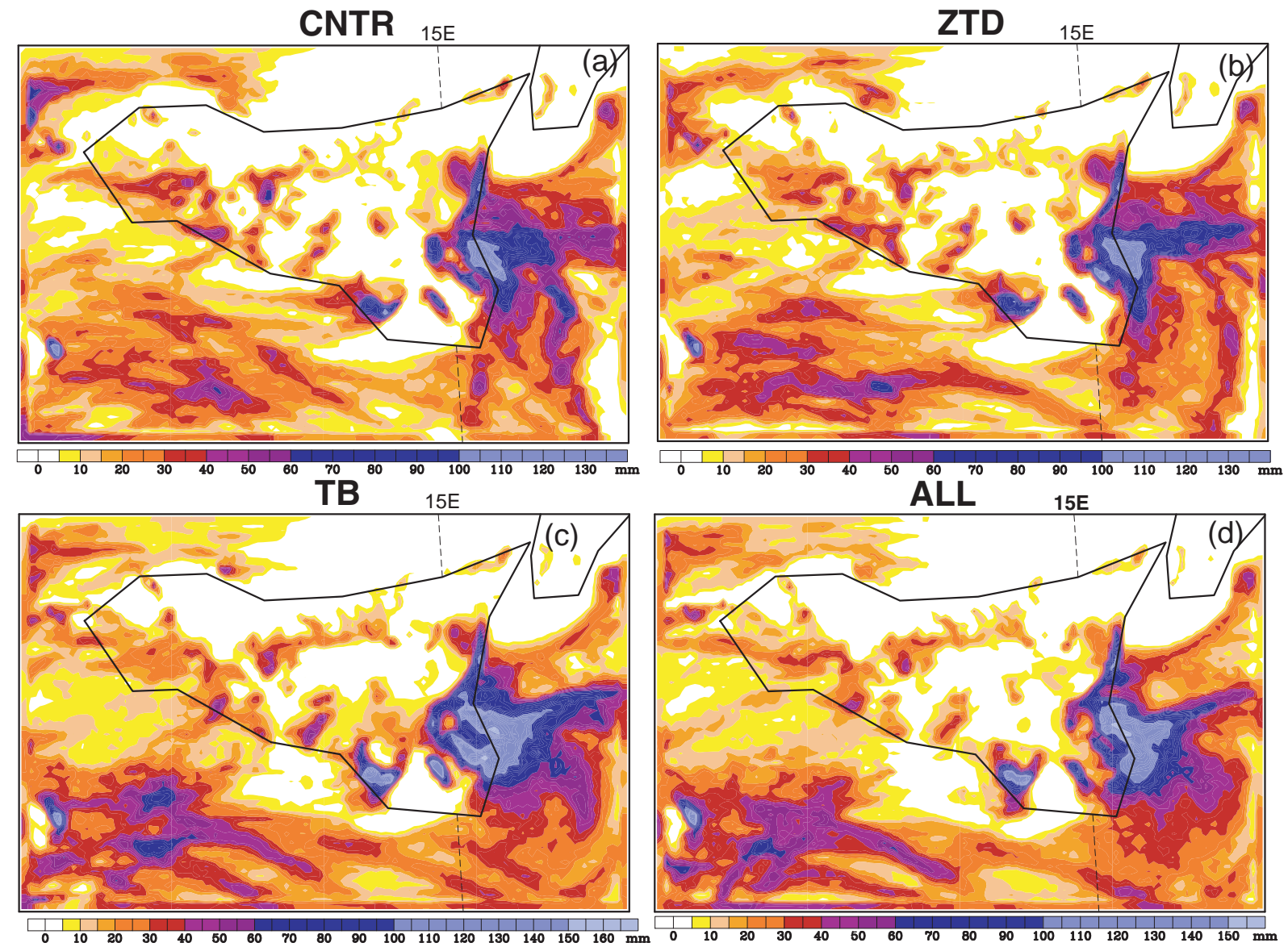

Fig. 7. $24 \mathrm{~h}$ accumulated precipitation for the MM5 experiments: (a) CNTR; (b) assimilation of GPS ZTD; (c) assimilation of SSM/I; (d) assimilation of the available data.

The ECMWF implementation of three-dimensional variational assimilation (3D-Var). I: Formulation., Q. J. R. Meteorol. Soc., 124, 1783-1807, 1998.

Doswell III, C. A., Ramis, C., Romero, R., and Alonso, S.: A Diagnostic Study of Three Heavy Precipitation Episodes in the Western Mediterranean Region, Weather and Forecasting, 13, 102124, 1998.

Dudhia, J.: A nonhydrostatic version of the Penn State-NCAR Mesoscale Model: Validation tests and simulation of an Atlantic cyclone and cold front, Mon. Wea. Rev., 121, 1493-1513, 1993.

Faccani, C. and Ferretti, R.: Data assimilation of high density observations: Part I. Impact on the initial conditions for the MAP/SOP IOP2b, Quarterly Journal of the Royal Meteorological Society, In Print, 2004.

Faccani, C., Cimini, D., Ferretti, R., Marzano, F., and Taramasso, A.: 3DVAR assimilation of SSM/I data for IOP2b MAP case, Adv. Geosci., in print, 2005.

Ferretti, R. and Faccani, C.: Data assimilation of high density observations: II. Impact on the forecast of the precipitation for the MAP/SOP IOP2b, Quarterly Journal of the Royal Meteorological Society, in print, 2005.

Grell, G., Dudhia, J., and Stauffer, D.: A Description of the FifthGeneration Penn State/NCAR Mesoscale Model (MM5)., NCAR Tech. Note NCAR/Tn-398+STR, 1994.
Gustafsson, N., Berre, L., Hörnqvist, S., Huang, X.-Y., Lindskog, M., B.Navascue, Mogensen, K. S., and Thorsteinsson, S.: Three-dimensional variational data assimilation for a limited area model. Part I: General formulation and the background error constraint, Tellus, 53A, 425-446, 2001.

Hong, Y. and Pan, H.: Non-local Boundary Layer vertical diffusion in a medium range forecast model, Mon. Wea. Rev., 124, 2322 2339, 1996.

Kain, J. S. and Fritsch, J. M.: A one-dimensional entraining/detraining plume model and its application in convective parameterization, J. Atmos. Sci., 47, 2784-2802, 1990.

Reisner, J., Rasmussen, R., and Bruintjes, R.: Explicit forecasting of supercooled liquid water in winter storms using the MM5 mesoscale model, Q. J. R. Meteorol. Soc., 124B, 1071-1107, 1998.

Rotunno, R. and Ferretti, R.: Mechanisms Of Intense Alpine Rainfall, Journal of the Atmospheric Sciences, 58, 1732-1749, 2001.

Rotunno, R. and Ferretti, R.: Comparative Analysis of Rainfall in MAP Cases IOP2b and IOP8, Quarterly Journal of the Royal Meteorological Society, 129B, 373-390, 2003.

Troen, I. and Mahrt, L.: A simple model of the atmospheric boundary layer: Sensitivity to surface evaporation., Bound.-Layer Meteor., 37, 129-148, 1986. 